\title{
Bone Regeneration Therapy of Atraumatic Necrosis of Femoral Head
}

Z. ZHAO*

Department of Joint Surgery, Xintai City People's Hospital, No. 1329, Xinfu Road, Xintai City, Shandong Province 271200, China

\section{Zhao et al.: Bone regeneration therapy of femoral head}

\begin{abstract}
Femoral head necrosis is a mobility disorder and till now no satisfactory solution has been reported. The principal contributing factor in the pathogenesis of the disease is insufficient blood supply to the femoral head resulting in necrosis of the femoral head. Various preventive measures required to treat femoral head necrosis include revascularization, adequate supply of osteogenic cells and establishing enough strength to avoid collapse. Among all, cell transplantation therapy is considered the most favourable treatment strategy for femoral head necrosis. However, the results merely depend on the etiology and the clinical stage of femoral head necrosis. Thus, it is better to make a treatment plan according to the epidemiology, disease status and stage. The main objective of this communication is to study the treatment of femoral head necrosis with cell replacement therapy and also its effects by focusing on the disease stages.
\end{abstract}

Key words: Femoral head necrosis, clinical stages, bone marrow transplant, cell-based therapy, radiographic evaluation, mesenchymal stem cells

Femoral head necrosis (FHN) is a mobility disorder, associated with hip joint ${ }^{[1,2]}$. According to an estimate, $70 \%$ of the individuals diagnosed with FHN progress to develop the collapse of the femoral head. Thus, after 3 to $4 \mathrm{y}$ of diagnosis, prosthetic joint replacement therapy is required for the stress-free movement ${ }^{[3,4]}$. FHN is not the disease of aging people, it is more prevalent in males aged between 30 to $40 \mathrm{y}$ than females. It has also been documented fact that $75 \%$ of cases of FHN are due to the involvement of bilateral joint ${ }^{[2]}$. Till now very little is known about the exact pathophysiology of the FHN. Although, a list of contributing factors such as sickle cell anaemia, use of steroids, femoral neck fractures are involved in the loss of osteogenic cells via obstructing blood supply especially in the greater trochanteric region $^{[1,2]}$. Published opinions regarding this disease represent that there are $59 \%$ of cases that proceed to symptomatic disease, which results in femoral head collaps $^{[5]}$. The prognosis of the disease may vary differentially based on the causes and conditions of diseases. The risks of collapse in FHN increases due to many factors such as sickle cell anemia, which increase the risk of collapse up to $73 \%$. Similarly, the risk also increases due to an increase in alcohol consumption $(47 \%)$ and renal failure (46\%). Corticosteroid use also increases the risk of up to $26 \%$ while atraumatic FHN is similar to the overall prevalence of bone collapse (38\%). HIV infected individuals have a lower risk of collapse due to FHN, about $15 \%$, and for lupus erythematosus patients the risk is relatively low at $7 \%$ as compared to the overall occurrence of collapse due to $\mathrm{FHN}^{[5]}$. Thus, it is necessary to consider the diseaserelated etiological factors to make a treatment plan.

There are various methodologies adopted to treat FHN, which included surgical or non-surgical treatments. The disease progression with non-surgical treatment procedures has shown very limited success ${ }^{[2]}$. Therefore, the United States has decreased the use of early hip osteoarthritis surgery intended to preserve joint, which was considered as the most desirable treatment strategy in $25 \%$ of FHN cases in 1992. Thus with time in 2008 , only $12 \%$ of cases underwent joint preserving procedures. However, at the same time total hip replacement increased from 1992 to 2008, an increase from 75 to $88 \%{ }^{[6]}$.

\section{Radiographic investigation for disease staging:}

In order to classify FHN into different clinical stages, the Ficat and ARCO (Association Research Circulation 
Osseous) classification system was used, on the basis of radiographic evaluation of the femoral head. For that purpose, bone scintigraphy and magnetic resonance imaging (MRI), are used to understand the basic concept and compare the changes occur in each clinical stage of $\mathrm{FHN}^{[7-9]}$. These radiographic images are assessed from every aspect like anterior or posterior and then categorize into its specific stage. This information helps to comprehend the prognosis of FHN for the preparation of a basic treatment plan for the patients (Table 1$)^{[10,11]}$. Thus FHN cases are categorized into 5 different stages. Stage 1 is considered as the earliest clinical stage in which the osteonecrotic lesions can be detected by bone scintigraphy and MRI. In this stage, osteonecrotic lesion show some marginal reaction on T1 weighed images and represents itself as a band of low signal intensity and on the other hand, T2 weighed images showed a band of high signal intensity.

Stage 2 occurs when clinical signs persist and radiograph shows definite areas of sclerosis with lucency on radiographs. In this stage, the necrotic portion is repaired by supplying adequate blood to the necrotic zone along with the deposition of dead cancellous bone towards the margin of the interface, which was generated by fibrous or laminar tissue during this process. In stage 3 , the subchondral fracture seems in a different manner on the radiograph and looks like a crescent image. Thus stage 3 can be further subdivided into $3 \mathrm{~A}$ and $3 \mathrm{~B}$ in which if the collapse in the femoral head is $<3 \mathrm{~mm}$, it is $3 \mathrm{~A}$ stage, while the $3 \mathrm{~B}$ stage is when the collapse is $\geq 3 \mathrm{~mm}$. Stage 4 , the terminal stage causes narrow spacing in the osteoarthritic joints due to osteophyte formation. Thus Steinberg's classification clarified that after an advanced stage of stage 5 of osteoarthritis alteration in bones occurs at its maximum.

Specific Disease Investigation Committee (SDIC) explains FHN in terms of radiographic classification under the guidance of the Japanese Ministry of Health,
Labour and Welfare that disease progresses represent the degree of weight put on the femoral head, adopted from a previous report (fig. 1). Radiographs are analyzed through three sites to find out the disease progression, these are anterior, plane and posterior. However, three different types of lesions are also explained to define the definite site of disease progression ${ }^{[9-11]}$. Type A lesion covers less surface almost one-third of the femoral head, on the other hand, type B lesion covers two-third of the weight-bearing surface. Similarly, type $\mathrm{C}$ occupies higher than two-third of the weight lifting area, which is further categorized into $\mathrm{C} 1$ and $\mathrm{C} 2$ lesions. $\mathrm{C} 1$ lesions do not spread anywhere while $\mathrm{C} 2$ lesions expand laterally to the border of the acetabulum. According to a published report, the risk of collapse for type A is $9 \%$, type B is $19 \%$ and $59 \%$ for type $\mathrm{C}$.

\section{Femoral head osteonecrosis treatment without using cells:}

Several non-surgical treatment strategies are used to make a strain-free femoral head and limit disease advancement. These strategies include modification in activity, physical therapy and restriction of weight lifting $^{[2]}$. When FHN gets initiated and reached at ARCO stage 1, the intramedullary pressure increases rapidly due to FHN thus the femoral head is drilled with core decompression method into a depth of 6 to 8 $\mathrm{mm}$ with the help of short trephine drill, which leads to decrease in intramedullary pressure of femoral head ${ }^{[7]}$. Core decompression treatment is a modern treatment strategy, which is much better than any conservative treatment. Core decompression treatment gave satisfactory results of $63.5 \%$ at initial stages of FHN while conventional treatment methods gave only 22.7 $\%$ of results ${ }^{[11,12]}$. Still, the advantages associated with the core decompression method have been ignored ${ }^{[13,14]}$. However, the core decompression method only employed in initial stages and avoided in progressive stages of treatment. It was already documented that the

TABLE 1: ASSOCIATION RESEARCH CIRCULATION OSSEOUS (ARCO) AND STEINBERG STAGING OF BONE NECROSIS

\begin{tabular}{|c|c|c|}
\hline Stages & Steinberg & ARCO \\
\hline Stage I & Normal radiographs & Normal radiographs \\
\hline Stage II & Sclerotic and cystic alterations & Sclerosis \\
\hline Stage III & Subchondral collapse & $\begin{array}{c}\text { Femoral head collapse, “crescent sign," no joint } \\
\text { space narrowing, Collapse }<3 \mathrm{~mm} \text { (stage IIIA), } \\
\text { Collapse }>3 \mathrm{~mm} \text { (stage IIIB) }\end{array}$ \\
\hline Stage IV & $\begin{array}{c}\text { Subchondral collapse, femoral head flattening, } \\
\text { normal space between joints }\end{array}$ & Osteoarthritic deteriorative alterations \\
\hline Stage V & $\begin{array}{l}\text { Flattening and tightening of joint space, acetabular } \\
\text { modifications }\end{array}$ & \\
\hline Stage VI & Advanced degenerative alterations, Osteoarthritis & \\
\hline
\end{tabular}




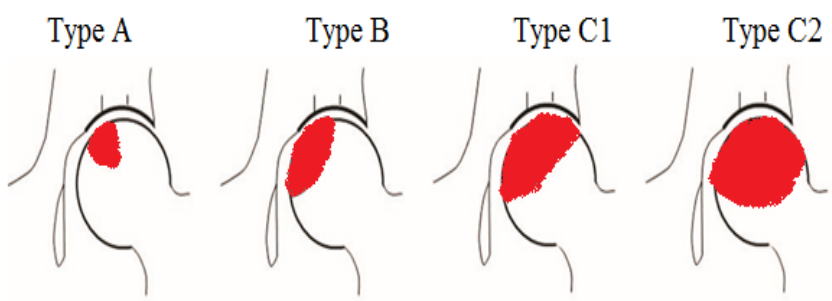

Fig. 1: Clinical staging of femoral head osteoarthritis Radiography-based clinical staging of femoral head osteoarthritis, issued by the Japanese Ministry of Health, Labour and Welfare.

core decompression method gives different results at different clinical stages of FHN and could give adequate benefits. At Steinberg stage 3 of FHN, $29 \%$ of patients recover with core decompression method, while at stage 3 and 4 of FHN 41 and $92 \%$ of patients require arthroplasty, respectively ${ }^{[15]}$. When FHN progresses to an advanced stage, bone fragility becomes the most important criteria to be considered in spite of the intrafemoral pressure exerted on the femoral head.

In the advanced stage of FHN, chances of micro fractures of subchondral bone are increased, so it is mandatory to strengthen the initial bone health to avoid unfavourable circumstances ${ }^{[16]}$.

Thus for this purpose vascularized bone grafts could play a vital role at advanced stages of FHN. When both arteries and veins are anastomosed during transplantation, approximately $90 \%$ of the osteocytes survive and there is no osteoclastic resorption of the bone for incorporation. Vascularized bone grafts have been shown to be biomechanically superior. Thus, it is concluded that vascularized bone graft gives satisfactory results in an advanced stage of femoral head necrosis. In fact, use of vascular bone grafts in this advanced stage of FHN is a great difficulty. Another study stated the probable results of using vascularized bone grafts through a radiographic investigation. Thus, it is concluded that vascularized bone graft does not give satisfactory results in an advanced stage of femoral head necrosis ${ }^{[2,17-19]}$.

\section{Femoral head osteonecrosis treatment through bone-marrow transplantation:}

The core decompression process is involved in decreasing intramedullary pressure along with an increase in the transport of living cells in a necrotic zone. Though FHN is not localized in a specific area, yet it disperses in the complete greater trochanteric area (GTA), which leads to a decrease in osteogenic cells throughout $\mathrm{GTA}^{[20,21]}$. Thus to increase the osteogenic cells in the trochanteric area, 2 other studies collaboratively described transplantation of concentrated bone marrow from the crest of the ilium using core decompression ${ }^{[22,23]}$. Thus, a study described that it is better to adopt concentrated bone marrow transplantation along with core decompression as compared to the decompression method alone especially in the initial stage of FHN as it can prolong the progress towards femoral head collapse. It was also reported that the collapse rate decrease with the use of bone marrow graft $(10 \%)$ while with the core decompression method alone the collapse rate was $63 \%$. After that, a series of studies were conducted, which focussed on the benefits of bone marrow grafting, which are discussed in fig. 2 and Table $2^{[23-28]}$. Thus the combinatory study of cell transplantation and core decompression gave acceptable results, which were further approved in clinical trials and were reported as a treatment strategy in of FHN in the initial stages, However, this combination was not approved to combat the collapse of the femoral head. A previous study thus linked different clinical stages of FHN with the effects of combined treatment and reported that 77,74 and $0 \%$ at stages 1, 2 and 3, respectively were prevented from collapse after combination therapy ${ }^{[2]}$. Thus, supplementary treatment is also applied to further increase the benefits associated with bone marrow grafts. Similarly, another study described the utilization of the technique of bone marrow graft along with platelet-rich plasma, which acts as an analgesic for $86 \%$ of patients and prevents collapse in $79 \%$ of patients. Afterward, another group of investigators used the technique of bone marrow transplantation with cancellous bone graft after core decompression method for both initial and advanced stage of FHN, which gave desirable clinical outcomes, according to which, the recovery rate was $80 \%$ in stage 1 and 65.7 in stage 2, while in stage 3, the rate was $38.9 \%$ and $33.3 \%$ in stage 4 . Thus the evidence obtained from this research study indicated that in the progressive stage of FHN, it is better to regain initial strength of the femoral head to avoid any fracture. Thus the initial strength can be achieved by bioactive scaffolding. In another study, FHN was treated at stages 1, 2 and 3A with concentrated bone marrow transplantation coupled with interconnected porous calcium hydroxyapatite. The results indicated that $56.7 \%$ of cases did not advance towards collapse, while mild collapse was seen in $33.3 \%$ of cases with $<2 \mathrm{~mm}$, however, $10 \%$ of cases have collapse $>2 \mathrm{~mm}$. A previously reported study described treatment of patients in 2 treatment groups, one with porous hydroxyapatite in combination with bone marrow transplantation while in the other 
treatment group hydroxyapatite was used alone at stage 2 . The results indicated that $78.6 \%$ of patients receiving combination treatment did not progress towards collapse as compared to $41.7 \%$ of patients who were treated only with bone marrow graft. This study stated that histological study of the femoral head indicated that even after the clinical recovery of FHN, it still showed signs of osteomalacia and osteoporosis ${ }^{[29-35]}$. Thus this problem was described in a study that reported another technique of curettage of the necrotic zone despite the bone decompression method ${ }^{[36]}$.

\section{Femoral head osteonecrosis treatment through mesenchymal stromal cell transplantation:}

When bone marrow graft and core decompression techniques failed to give desired results, but showed a lesser number of osteogenic cells in necrotic patients. According to reported study, individuals with a history of steroid or alcohol use or any organ transplant have lesser number of osteogenic cells present in bone marrow. Thus, to combat this situation MSCs were used $^{[22]}$.

MSCs are used to regrow musculoskeletal tissues. Morphologically MSCs are elongated-nucleated adherent cells, which are categorized into osteogenic cells, adipogenic cells and chondrogenic cells. These cells can proliferate which results in the production of a large number of cells. This proliferative property of cells can regenerate lost cells in the femoral region. MSCs also have the ability to distinguish the vascular and avascular endothelial cells. This ability to differentiate help MSCs to treat interrupted blood supply to the FHN zone. MSCs can be distinguished from other tissues and bone marrow. The ideal source for MSC differentiation and proliferation remains controversial. However, the strategy to draw bone marrow is relatively safe and effective ${ }^{[37-43]}$.

Few studies reported the use of MSCs for treatment purposes in clinical trials and the results are shown in fig. 2 and Table 2. The comparison between transplanted cultured MSCs and bone marrow cells with core decompression in the initial stages of FHN have been documented. The findings showed that after $5 \mathrm{y}$ only $4 \%$ of FHN patients treated with MSCs advanced towards collapse while $23 \%$ of patients treated with bone marrow transplant progressed towards collapse. A recent study also compared MSCs treatment with bone marrow transplant in both early and advanced stage of FHN, while another study did not find any variation in results regarding the collapse rate between both treatment groups in comparison to a reported study in which both treatment groups had $0 \%$ collapse rate at initial stage $1,18 \%$ at stage 2 and at stage 3 the MSCstreated group showed $20 \%$ collapse rate in comparison to the bone marrow group with a collapse rate of $25 \%$. A different study also reported that MSCs with core decompression method is not adequate enough to

TABLE 2: USE OF CELLS WITH THE STAGE OF FEMORAL HEAD OSTEONECROSIS

\begin{tabular}{lc}
\hline Cell source & Surgical technique \\
\hline $\begin{array}{l}\text { Bone marrow } \\
\text { cells }\end{array}$ & $\begin{array}{c}\text { Core decompression } \\
\text { Core decompression+bioderived } \\
\text { material }\end{array}$ \\
& $\begin{array}{c}\text { Core decompression+bioactive } \\
\text { scaffold } \\
\text { Curettage+bone graft } \\
\text { Cosenchymal } \\
\text { stem cells (MSCs) }\end{array}$ \\
& $\begin{array}{c}\text { Curettage+bone graft+bioactive } \\
\text { scaffold }\end{array}$ \\
\hline
\end{tabular}
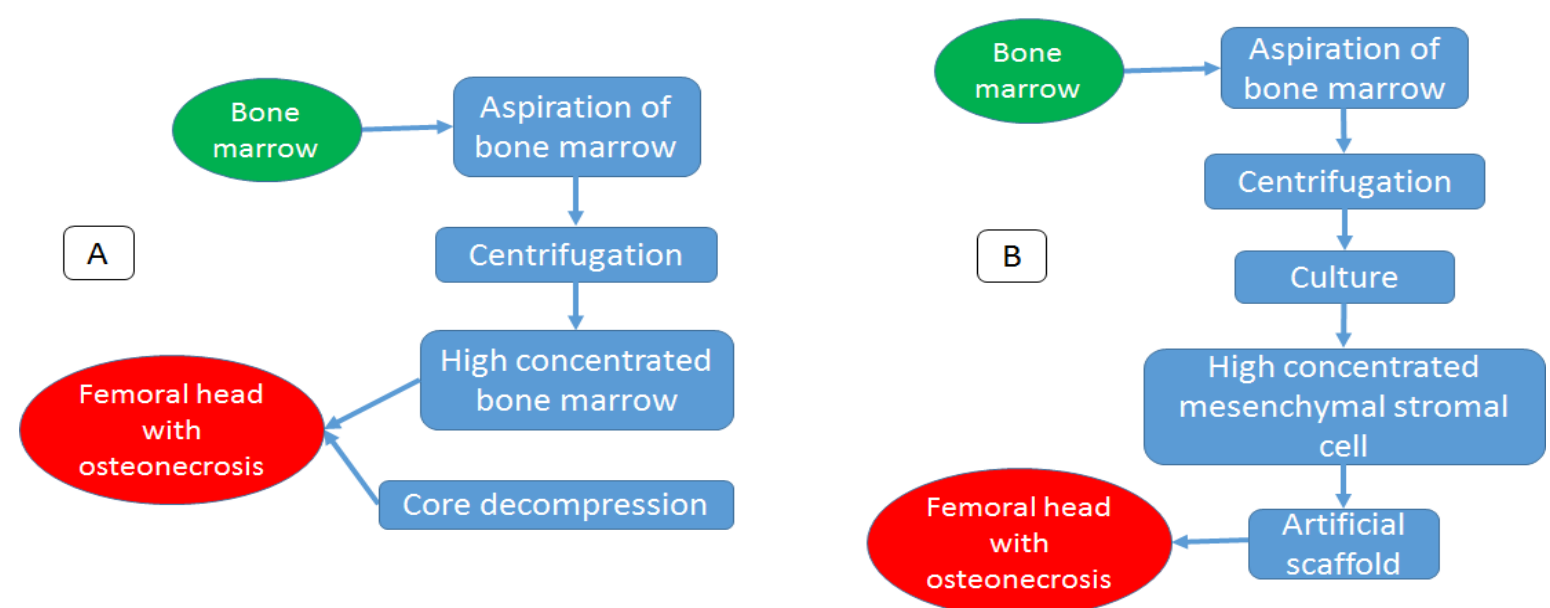

Fig. 2: Mechanism of cell-based treatment procedure in combination with bone marrow transplant

The mechanism of cell-based treatment procedure in combination with bone marrow transplant (A) The process of core decompression (B) Transplantation of mesenchymal stromal cells in combination with biomaterials after removal of necrotic bone. 103 
prevent the collapse rate at an advanced stage of FHN. Similarly, two other groups adopted a different treatment plan for FHN patients and started to treat necrotic bone with the curette process along with packed betatricalcium phosphate in combination with mesenchymal stem cells and vascularized bone implant. It was documented that there was no collapse progression of hip shown at stage $3 \mathrm{~A}$ in contrast to stage $3 \mathrm{~B}$, which showed a $50 \%$ collapse progression. However, another study did not describe any advancement towards collapse at FHN stage III or IV ${ }^{[44-48]}$.

\section{Femoral head osteonecrosis treatment by using cells:}

From the previous literature, it became evident the cells that can be distinguished from concentrated bone marrow cells (osteogenic) are beneficial for FHN treatment. Its preparation is easy and economical with low-risk, although, if the lesion is large and deep, a large number of cells are required. Condition and number of host tissue osteogenic cell is always a considerable factor for good results. Thus, the differentiation of MSCs into osteogenic cells and vascular endothelial cells assist in achieving benefits. MSCs use the cytokine and paracrine effect to produce a bulk of differentiated in vitro cell lineages. Though, the capability of differentiation of MSCs wholly depends on the age, medication and the health of the host ${ }^{[49-52]}$. Another treatment plan to treat FHN is the peripheral CD34-positive MSCs. These can be easily distinguished between vascular endothelial cells and osteogenic cells and can be prepared in vitro by induction of granulocyte colony-stimulating factors. In spite of various multiple sources of MSCs to treat osteonecrotic bone, bone remodelling being the subject of matter is the debatable topic. When talking about healthy tissue, there is always a balance between bone formation and resorption. While in a pathological condition of bone such as osteonecrosis, prolonged fracture repair, the balance between osteoclast and osteoblast is deregulated and reduced in number ${ }^{[35,53,54]}$. Thus, the necrotic bone should be removed to hasten recovery process. MSCs also have the ability to regulate osteoclastogenesis ${ }^{[55-57]}$. As a result, a healthy recovery of bone is achieved by the cytokine effect of MSCs.

\section{Femoral head osteonecrosis treatment by using biomaterials:}

The use of biomaterials has high clinical and social value to delay the total hip collapse. Presently biomaterials are upgraded to the extent that it can improve osteoinduction and osteoconduction in the femoral head ${ }^{[58,59]}$. In these biomaterials, porous tantalum rods gave outstanding results with improved osteoconductive property, its elasticity gives the consequences similar to human bone tissues ${ }^{[60]}$. Another study documented 50 cases of hips treated with tantalum rods and reported only $15.5 \%$ of cases converted to total hip arthroplasty. Another study described the comparison of core decompression method vs. patients treated with tantalum rod implantation in its initial staged of FHN. After treatment, both groups showed improvements in the radiographic examination. Another group of the researcher used tantalum rods in an advanced stage of stage 2 and 3 of FHN, in combination with bone marrow and autologous bone grafts. After $5 \mathrm{y}$ of treatment only 3 and $15 \%$ of cases in stages II and III, respectively were further shifted to total hip replacement ${ }^{[61-63]}$.

There are many other biodegradable materials used to treat FHN. These include nano-hydroxyapatite/ polyamide (n-HA/PA) $66 \operatorname{rods}^{[61,64]}$. Another study described the treatment of 84 cases of FHN into 2 groups, one of which was treated with core decompression method along with incorporation of n-HA/PA 66 rods and the other one was treated with core decompression in combination with autologous cancellous bone graft. In the first group treated with n-HA/PA 66 rods, $21.1 \%$ of patients progressed towards collapse as compared to bone grafting patients that showed $45.7 \%$ of patients progressed towards femoral head collapse. Biomaterials have the elasticity of changing their morphology to fill cavities between bones, which are considered as one of the main advantages of biomaterials. There are a series of reports, which documented the use of various biomaterials in FHN patients. The researchers treated patients with porous hydroxyapatite rods; with composite filler, with porous beta-tricalcium phosphate granules along with cultured MSCs ${ }^{[31,32,47,48]}$. However, there are several benefits of using biomaterials in combination with the cell transplant method, still to observe the balance between degradation time and osteogenesis is an important consideration factor. Another influential factor is osteoclast, which influences the activity of biomaterials ${ }^{[65]}$. Biomaterials are responsible for the early resorption of bone as compared to bone formation, thus, as a result, it cannot prevent collapse. Consequently, the combinations with biomaterials should be analyzed closely.

\section{Femoral head osteonecrosis treatment through growth factors:}

FHN is a serious issue have been tried to resolve from ages with various treatment methods, incorporation of 
growth factor is one of the popular treatment methods. These growth factors include platelet-derived growth factor, fibroblast growth factor-2 (FGF-2) and vascular endothelial growth factors. The purpose of the usage of these growth factors is to improve revascularization and bone remodeling with FHN. Studies carried out on BMP-2 and BMP-6, it was stated that BMP-2 and BMP6 if down-regulated in FHN patents can be used as a treatment purpose. The investigators treated patients with BMP-2 replacement along with allogenic fibula transplantation, concluded according to radiographic study that $17.6 \%$ of FHN patients progressed to collapse at stages 2 and 3 . The researchers treated FHN patients with two treatment groups, one of which is BMP-2 treatment along with artificial bone graft and the other one is the insertion of single artificial bone. The combinatory group of BMP-2 with artificial bone implants came up with a different percent of survival rate at different stages of $\mathrm{FHN}^{[66-69]}$. At ARCO $2 \mathrm{~b}$ stage the survival rate was $100 \%$, at ARCO 2C stage the survival rate was $84.2 \%$, while at ARCO stage 3 the survival percentage was $30 \%$. While in comparison to the insertion of separate artificial bone the survival frequency for ARCO stages 2b, 2c, and 3 was 100, 76.5 and $37.5 \%$, respectively. Thus it was concluded that BMP-2 was much more beneficial. The researchers treated FHN patients with BMP-7 along with autologous, non-vascularized fibular grafts at Steinberg stage 2 and 3. After 4 y of treatment, it was found that a total of $29 \%$ of patients advanced towards collapse. It was also concluded that this combination can also be used in short surgical procedures and rehabilitation period after surgery. Another study mentioned the treatment of patients in the initial stage of FHN and treated them with recombinant FGF-2 impregnated with gelatin hydrogel, thus after $1 \mathrm{y}$ of treatment, $10 \%$ of total hips advanced towards collapse. The researchers found a high level of interleukin- 6 and tumor necrosis factor- $\alpha$ at an advanced stage of FHN. Thus it was found that cytokine activity accelerated when used in combination with growth factor, which can be further used in future studies $^{[70-76]}$.

\section{CONCLUSION}

FHN is a pathological process that progresses towards the collapse of the femoral head if untreated. In this review, various treatment strategies adopted by researchers were discussed to draw a conclusion. Thus conclusively delivery of osteogenic cells, revascularization and providing initial health to the femoral bone is included in the treatment plan to the challenges successfully. Thus new techniques should be developed into consideration with the pathology and clinical outcomes associated with these techniques.

\section{REFERENCES}

1. Agarwala S, Vijayvargiya M. Bisphosphonate combination therapy for non-femoral avascular necrosis. J Orthop Surg Res 2019;14:1152-7.

2. Kaushik AP, Das A, Cui Q. Osteonecrosis of the femoral head: an update in y 2012. World J Orthop 2012;3:49-57.

3. Andriolo L, Merli G, Tobar C, Altamura SA, Kon E, Filardo G. Correction to: regenerative therapies increase survivorship of avascular necrosis of the femoral head: A systematic review and meta-analysis. Int Orthop 2019;43:505.

4. Steinberg ME, Steinberg DR. Classification systems for osteonecrosis: An overview. Orthop Clin North Am 2004;35:273-83.

5. Mont MA, Zywiel MG, Marker DR, McGrath MS, Delanois RE. The natural history of untreated asymptomatic osteonecrosis of the femoral head: A systematic literature review. J Bone Joint Surg Am 2010;92:2165-70.

6. Johnson AJ, Mont MA, Tsao AK, Jones LC. Treatment of femoral head osteonecrosis in the United States: 16-y analysis of the Nationwide Inpatient Sample. Clin Orthop Relat Res 2014;472:617-23.

7. Ficat RP. Idiopathic bone necrosis of the femoral head. Early diagnosis and treatment. J Bone Joint Surg Br 1985;67:3-9.

8. Steinberg ME. Classification of avascular necrosis: a comparative study. Acta Orthop Belg 1999;65:45-6.

9. Sugano N, Atsumi T, Ohzono K, Kubo T, Hotokebuchi T, Takaoka K. The 2001 revised criteria for diagnosis, classification, and staging of idiopathic osteonecrosis of the femoral head. J Orthop Sci 2002;7:601-5.

10. Nishii T, Sugano N, Ohzono K, Sakai T, Haraguchi K, Yoshikawa H. Progression and cessation of collapse in osteonecrosis of the femoral head. Clin Orthop Relat Res 2002;400:149-57.

11. Aoyama T. A Strategy of Bone Regeneration for the Treatment of Idiopathic Femoral Head Necrosis. In Advanced Techniques in Bone Regeneration by Alessandro Rozim Zorzi. InTechOpen Publisher; 2016.

12. Atilla B, Bakircioglu S, Shope AJ, Parvizi J. Joint-preserving procedures for osteonecrosis of the femoral head. EFORT Open Rev 2019;4:647-58.

13. Rajagopal M, Balch Samora J, Ellis TJ. Efficacy of core decompression as treatment for osteonecrosis of the hip: a systematic review. Hip Int 2012;22:489-93.

14. Neumayr LD, Aguilar C, Earles AN, Jergesen HE, Haberkern CM, Kammen BF, et al. National Osteonecrosis Trial in Sickle Cell Anemia Study Group. Physical therapy alone compared with core decompression and physical therapy for femoral head osteonecrosis in sickle cell disease. Results of a multicenter study at a mean of three y after treatment. J Bone Joint Surg Am 2006;88:2573-82.

15. Barney J, Piuzzi NS, Akhondi H. Femoral Head Avascular Necrosis. In: StatPearls Treasure Island. StatPearls Publishing; 2020.

16. Meier R, Kraus TM, Schaeffeler C, Torka S, Schlitter AM, Specht $\mathrm{K}$, et al. Bone marrow oedema on MR imaging indicates ARCO stage 3 disease in patients with AVN of the femoral head. Eur Radiol 2014;24: 2271-8.

17. Petek D, Hannouche D, Suva D. Osteonecrosis of the femoral 
head: pathophysiology and current concepts of treatment. EFORT Open Rev 2019;4:85-97.

18. Aldridge JM, Urbaniak JR. Vascularized fibular grafting for osteonecrosis of the femoral head with unusual indications. Clin Orthop Relat Res 2008;466:1117-24.

19. Korompilias AV, Lykissas MG, Beris AE, Urbaniak JR, Soucacos PN. Vascularised fibular graft in the management of femoral head osteonecrosis: twenty y later. J Bone Joint Surg Br 2009;91:287-93.

20. Gangji V, Hauzeur JP, Schoutens A, Hinsenkamp M, Appelboom T, Egrise D. Abnormalities in the replicative capacity of osteoblastic cells in the proximal femur of patients with osteonecrosis of the femoral head. J Rheumatol 2003;30:348-51.

21. Feng W, Chen J, Wu K. A comparative study of corticocancellous iliac bone graft with or without the combination of vascularized greater trochanter flap for the management of femoral head osteonecrosis: A minimum 6 y follow-up. BMC Musculoskelet Disord 2019;20:298.

22. Hernigou P, Beaujean F. Treatment of osteonecrosis with autologous bone marrow grafting. Clin Orthop Relat Res 2002;405:14-23.

23. Gangji V, Hauzeur JP, Matos C, De Maertelaer V, Toungouz M, Lambermont M. Treatment of osteonecrosis of the femoral head with implantation of autologous bone marrow cells. A pilot study. J Bone Joint Surg Am 2004;6:1153-60.

24. Wang BL, Sun W, Shi ZC, Zhang NF, Yue DB, Guo WS, et al. Treatment of nontraumatic osteonecrosis of the femoral head with the implantation of core decompression and concentrated autologous bone marrow containing mononuclear cells. Arch Orthop Trauma Surg 2010;130:859-65.

25. Chotivichit A, Korwutthikulrangsri E, Pornrattanamaneewong C, Achawakulthep C. Core decompression with bone marrow injection for the treatment of femoral head osteonecrosis. J Med Assoc Thai 2014;97:139-43.

26. Mao Q, Jin H, Liao F, Xiao L, Chen D, Tong P. The efficacy of targeted intraarterial delivery of concentrated autologous bone marrow containing mononuclear cells in the treatment of osteonecrosis of the femoral head: A five y follow-up study. Bone 2013;57:509-16.

27. Ma Y, Wang T, Liao J, Gu H, Lin X, Jiang Q, et al. Efficacy of autologous bone marrow buffy coat grafting combined with core decompression in patients with avascular necrosis of femoral head: A prospective, double-blinded, randomized, controlled study. Stem Cell Res Ther 2014;5:115.

28. Tabatabaee RM, Saberi S, Parvizi J, Mortazavi SM, Farzan M. Combining concentrated autologous bone marrow stem cells injection with core decompression improves outcome for patients with early-stage osteonecrosis of the femoral head: A comparative study. J Arthroplasty 2015;30:11-5.

29. Martin JR, Houdek MT, Sierra RJ. Use of concentrated bone marrow aspirate and platelet rich plasma during minimally invasive decompression of the femoral head in the treatment of osteonecrosis. Croat Med J 2013;54:219-24.

30. Kang JS, Moon KH, Kim BS, Kwon DG, Shin SH, Shin BK, et al. Clinical results of auto-iliac cancellous bone grafts combined with implantation of autologous bone marrow cells for osteonecrosis of the femoral head: A minimum $5 \mathrm{y}$ followup. Yonsei Med J 2013;54:510-15.

31. Yamasaki T, Yasunaga Y, Ishikawa M, Hamaki T, Ochi M. Bone-marrow-derived mononuclear cells with a porous hydroxyapatite scaffold for the treatment of osteonecrosis of the femoral head: A preliminary study. J Bone Joint Surg Br 2010;92:337-41.

32. Liu Y, Liu S, Su X. Core decompression and implantation of bone marrow mononuclear cells with porous hydroxylapatite composite filler for the treatment of osteonecrosis of the femoral head. Arch Orthop Trauma Surg 2013;133:125-33.

33. Graber M, Johnson DE. Anterior Hip (Femur) Dislocation. In: StatPearls Treasure Island. StatPearls Publishing; 2020.

34. Gangji V, Hauzeur JP. Cellular-based therapy for osteonecrosis. Orthop Clin North Am 2009;40:213-21.

35. Chim SM, Tickner J, Chow ST, Kuek V, Guo B, Zhang G, et al. Angiogenic factors in bone local environment. Cytokine Growth Factor Rev 2013;24: 297-310.

36. Wang T, Wang W, Yin ZS. Treatment of osteonecrosis of the femoral head with thorough debridement, bone grafting and bone-marrow mononuclear cells implantation. Eur J Orthop Surg Traumatol 2014;24:197-202.

37. Steinert AF, Rackwitz L, Gilbert F, Noth U, Tuan RS. Concise review: The clinical application of mesenchymal stem cells for musculoskeletal regeneration: current status and perspectives. Stem Cells Transl Med 2012;1:237-47.

38. Guo HS, Tian YJ, Liu G, An L, Zhou ZG, Liu HZ. Arthroscopyguided core decompression and bone grafting combined with selective arterial infusion for treatment of early stage avascular necrosis of femoral head. China J Orthop Trauma 2018;31:5660.

39. Dominici M, Le Blanc K, Mueller I, Slaper-Cortenbach I, Marini F, Krause D, et al. Minimal criteria for defining multipotent mesenchymal stromal cells. The International Society for Cellular Therapy position statement. Cytotherapy 2006;8:315-7.

40. Prough H, Alsayouri K. Anatomy, Bony Pelvis and Lower Limb, Lateral Circumflex Femoral Artery. In: StatPearls Treasure Island. StatPearls Publishing; 2020.

41. Wang Z, Sun QM, Zhang FQ, Zhang QL, Wang LG, Wang WJ. Core decompression combined with autologous bone marrow stem cells versus core decompression alone for patients with osteonecrosis of the femoral head: A meta-analysis. Int J Surg 2019;69:23-31.

42. Mohal JS, Tailor HD, Khan WS. Sources of adult mesenchymal stem cells and their applicability for musculoskeletal applications. Curr Stem Cell Res Ther 2012;7:103-9.

43. Hernigou J, Alves A, Homma Y, Guissou I, Hernigou P. Anatomy of the ilium for bone marrow aspiration: map of sectors and implication for safe trocar placement. Int Orthop 2014;38:2585-90.

44. Zhao D, Cui D, Wang B, Tian F, Guo L, Yang L, et al. Treatment of early stage osteonecrosis of the femoral head with autologous implantation of bone marrow-derived and cultured mesenchymal stem cells. Bone. 2012;50:325-30.

45. Rastogi S, Sankineani SR, Nag HL, Mohanty S, Shivanand $\mathrm{G}$, Marimuthu K, et al. Intralesional autologous mesenchymal stem cells in management of osteonecrosis of femur: a preliminary study. Musculoskelet Surg 2013;97:223-8.

46. Persiani P, De Cristo C, Graci J, Noia G, GurziM, Villani C. Stage-related results in treatment of hip osteonecrosis with core-decompression and autologous mesenchymal stem cells. Acta Orthop Belg 2015;81:406-12.

47. Aoyama T, Goto K, Kakinoki R, Ikeguchi R, Ueda M, Kasai Y, et al. An exploratory clinical trial for idiopathic osteonecrosis of femoral head by cultured autologous multipotent mesenchymal stromal cells augmented with vascularized bone grafts. Tissue Eng 2014;20:233-42. 
48. Kawate K, Yajima H, Ohgushi H, Kotobuki N, Sugimoto K, Ohmura $\mathrm{T}$, et al. Tissue-engineered approach for the treatment of steroid-induced osteonecrosis of the femoral head: transplantation of autologous mesenchymal stem cells cultured with beta-tricalcium phosphate ceramics and free vascularized fibula. Artif Organs 2006;30:960-2.

49. Petek D, Hannouche D, Suva D. Osteonecrosis of the femoral head: pathophysiology and current concepts of treatment. EFORT Open Rev 2019;4:85-97.

50. Piuzzi NS, Anis HK, Muschler GF. Osteonecrosis of the femoral head with subchondral collapse. Cleve Clin J Med 2019;86:511-2.

51. Liang X, Ding Y, Zhang Y, Tse HF, Lian Q. Paracrine mechanisms of mesenchymal stem cell-based therapy: current status and perspectives. Cell Transplant 2014;23:1045-9.

52. Schimke MM, Marozin S, Lepperdinger G. Patient-specific age: The other side of the coin in advanced mesenchymal stem cell therapy. Front Physiol 2015;6:362.

53. Kuroda R, Matsumoto T, Kawakami Y, Fukui T, Mifune Y, Kurosaka M. Clinical impact of circulating CD34-positive cells on bone regeneration and healing. Tissue Eng Part B Rev 2014;20:190-9.

54. Xiao W, Li S, Pacios S, Wang Y, Graves DT. Bone remodeling under pathological conditions. Front Oral Biol 2015;18:17-27.

55. Ikeguchi R, Kakinoki R, Aoyama T, Shibata KR, Otsuka S, Fukiage $\mathrm{K}$, et al. Regeneration of osteonecrosis of canine scapho-lunate using bone marrow stromal cells: possible therapeutic approach for Kienbock disease. Cell Transplant 2006;15:411-22.

56. Bielby R, Jones E, McGonagle D. The role of mesenchymal stem cells in maintenance and repair of bone. Injury 2007;38:26-32.

57. Crane JL, Cao X. Bone marrow mesenchymal stem cells and TGF- $\beta$ signalling in bone remodelling. J Clin Invest 2014;124:466-72.

58. Lespasio MJ, Sodhi N, Mont MA. Osteonecrosis of the Hip: A Primer. Perm J 2019;23:5.

59. Petek D, Hannouche D, Suva D. Osteonecrosis of the femoral head: pathophysiology and current concepts of treatment. EFORT Open Rev 2019;4:85-97.

60. Bobyn JD, Poggie RA, Krygier JJ, Lewallen DG, Hanssen $\mathrm{AD}$, Lewis RJ, et al. Clinical validation of a structural porous tantalum biomaterial for adult reconstruction. J Bone Joint Surg Am 2004;86:123-9.

61. Veillette CJ, Mehdian H, Schemitsch EH, McKee MD. Survivorship analysis and radiographic outcome following tantalum rod insertion for osteonecrosis of the femoral head. $\mathrm{J}$ Bone Joint Surg Am 2006;88:48-55.

62. Miao H, Ye D, Liang W, Yao Y. Effect of osteonecrosis intervention rod versus core decompression using multiple small drill holes on early stages of necrosis of the femoral head: A prospective study on a series of 60 patients with a minimum 1-y-follow-up. Open Orthop J 2015;9:179-84.

63. Pakos EE, Megas P, Paschos NK, Syggelos SA, Kouzelis A, Georgiadis G, et al. Modified porous tantalum rod technique for the treatment of femoral head osteonecrosis. World $\mathrm{J}$ Orthop 2015;6:829-37.
64. Yang P, Bian C, Huang X, Shi A, Wang C, Wang K. Core decompression in combination with nano-hydroxyapatite/ polyamide 66 rod for the treatment of osteonecrosis of the femoral head. Arch Orthop Trauma Surg 2014;134:103-12.

65. Detsch R, Boccaccini AR. The role of osteoclasts in bone tissue engineering. J Tissue Eng Regen Med 2015;9:1133-49.

66. Rackwitz L, Eden L, Reppenhagen S, Reichert JC, Jakob F, Walles $\mathrm{H}$, et al. Stem cell- and growth factor-based regenerative therapies for avascular necrosis of the femoral head. Stem Cell Res Ther 2012;3:7.

67. Samara S, Dailiana Z, Varitimidis S, Chassanidis C, Koromila $\mathrm{T}$, Malizos KN, et al. Bone morphogenetic proteins (BMPs) expression in the femoral heads of patients with avascular necrosis. Mol Biol Rep 2013;40:4465-72.

68. Harrell CR, Markovic BS, Fellabaum C, Arsenijevic A, Volarevic V. Mesenchymal stem cell-based therapy of osteoarthritis: current knowledge and future perspectives. Biomed Pharmacother 2019;109:2318-26.

69. Lee YK, Lee B, Parvizi J, Ha YC, Koo KH. Which osteotomy for osteonecrosis of the femoral head and which patient for the osteotomy. Clin Orthop Surg 2019;11:137-41.

70. Papanagiotou M, Malizos KN, Vlychou M, Dailiana ZH. Autologous (non-vascularised) fibular grafting with recombinant bone morphogenetic protein-7 for the treatment of femoral head osteonecrosis: preliminary report. Bone Joint J 2014;96:31-5.

71. Hua K, Yang X, Feng J, Feng W, Li Y, Hao, et al. The efficacy and safety of core decompression for the treatment of femoral head necrosis: A systematic review and meta-analysis. J Orthop Surg Res 2019;14:306.

72. Abe H, Sakai T, Ando W, Takao M, Nishii T, Nakamura $\mathrm{N}$, et al. Synovial joint fluid cytokine levels in hip disease. Rheumatol 2014;53:165-72.

73. Sun H, Yang HL. Calcium phosphate scaffolds combined with bone morphogenetic proteins or mesenchymal stem cells in bone tissue engineering. Chin Med J 2015;128:1121-7.

74. Wu ZY, Sun Q, Liu M, Grottkau BE, He ZX, Zou Q, et al. Correlation between the efficacy of stem cell therapy for osteonecrosis of the femoral head and cell viability. BMC Musculoskelet Disord 2020;21:55.

75. Wu Y, Zhang C, Wu J, Han Y, Wu C. Angiogenesis and bone regeneration by mesenchymal stem cell transplantation with danshen in a rabbit model of avascular necrotic femoral head. Exp Ther Med 2019;18:163-71.

76. Zhao D, Wang B, Liu B. Vascularized iliac bone flap transfer for early and middle stages of osteonecrosis of the femoral head. JBJS Essent Surg Tech 2019;9:5.

This is an open access article distributed under the terms of the Creative Commons Attribution-NonCommercial-ShareAlike 3.0 License, which allows others to remix, tweak, and build upon the work non-commercially, as long as the author is credited and the new creations are licensed under the identical terms

This article was originally published in a special issue, "Biomedical research applications in Pharmaceutical Sciences" Indian J Pharm Sci 2020:82(2)Spl issue3;100-107 